\title{
ВЛИЯНИЕ ПРОФЕССИОНАЛЬНОГО СТАЖА МЕНЕДЖЕРОВ НА ИХ СКЛОННОСТЬ К МАНИПУЛЯЦИЯМ
}

\section{THE INFLUENCE OF THE PROFESSIONAL EXPERIENCE OF MANAGERS ON THEIR PROPENSITY TO MANIPULATE}

A. Kuteynikov

Summary: The article is devoted to the problem of formation of manipulative abilities in managers. The question is raised that in some areas of activity manipulation is a professionally important quality. The author considers the formation of manipulative abilities as a result of professional deformations.

The dependence of the level of formation of manipulative abilities on the length of service as a manager is analyzed. The author also offers a mathematical regression model of the dependence of the degree of manipulativeness in behavior on the professional experience of optants.

Keywords: manipulative behavior, Machiavellianism, professionally important qualities, the influence of the manager's profession on personal qualities, regression model.
И звестно, что, длительное пребывание специалиста в профессиональном пространстве формирует или трансформирует его определенные личностные качества. Насколько велико данное влияние? Какие черты личности заостряет эта профессиональная среда, а какие минимизирует? Разумеется, это зависит как от специфики самой профессии, так и от временного промежутка включенности в указанную профессию.

Указанная тема вызывает значительный интерес у специалистов. Следует сказать, что проблема манипулятивного управления в последнее время все чаще привлекает внимание психологов. В настоящей статье мы попытались дать ответ на вопрос относительно того, какое влияние оказывает профессия менеджера по продажам на их склонность к манипулятивному поведению.

Прежде чем рассмотреть манипулятивное поведение необходимо сказать несколько слов о манипулятивном общении. Первая точка зрения гласит, что целью манипулятивного общения является использование партнера в качестве средства, но так, чтобы собеседник этого не заметил. Вторая точка зрения в категорию манипуляций включает и шантажное поведение, и даже запугивание; то есть здесь к манипуляциям предлагается относить не только заведомый обман, но и такую ситуацию, когда собеседник все осознает, но не имеет сил или возможно-
Кутейников Алексей Николаевич

К.nсх.н., дочент, Северо-западный институт управления Российской академии народного хозяйства и государственной службы, Санкт-Петербург alex_kutejnikov@mail.ru

Аннотация: Статья посвящена проблеме формирования манипулятивных способностей у менеджеров. Ставится вопрос о том, что в некоторых сферах деятельности манипуляции являются профессионально важным качеством. Автор рассматривает формирование манипулятивных способностей как результат профессиональных деформаций.

Анализируется зависимость уровня сформированности манипулятивных способностей от стажа пребывания в должности менеджера. Автор также предлагает математическую регрессионную модель зависимости степени манипулятивности в поведении от профессионального стажа оптантов.

Ключевые слова: манипулятивное поведение, макиавеллизм, профессионально важные качества, влияние профессии менеджера на личностные качества, регрессионная модель.

сти отказать. В любом случае, партнер рассматривается как средство для достижения целей другого человека. Самым ярким апологетом манипулятивного общения, в том числе и применительно к процессу управления, является когда-то ненадолго популярный на просторах бывшего СССР Дейл Карнеги.

Технология манипулятивного общения Карнеги неоднократно подвергалась критике. Например, Э. Бёрн считал, что манипулятивное общение может принести тактический выигрыш, но в стратегическом плане оно ведет к проигрышу [1]. Об этом же говорит и отечественный психотерапевт М.Е. Литвак [3]. Е.Л. Доценко отмечает, что манипулятор может достаточно хорошо разбираться в слабостях других людей. Но наряду с этим манипулятор является плохим психологом, так как он не умеет разбираться в способностях людей (разбираться в слабостях людей и разбираться в их способностях- это принципиально разные вещи).

Э. Шостром великолепно описал психологический портрет манипулятора. Он отметил, что причиной является боязнь отвержения в общении. И активная вовлеченность в манипулятивное поведение приводит к деформациям в самой личности манипулятора. Так, для манипулятора характерны повышенная тревожность, чрезмерный самоконтроль, постоянная потребность 
произвести впечатление. Также для них характерны постоянный цинизм и деформации эмоциональной сферы [4].

Рано или поздно перед исследователем проблемы возникает вопрос: хорошо или плохо обладать развитыми манипулятивными способностями? В принципе, плохо. Это плохо для установления близких отношений, для упорядочивания семейной жизни. Но есть профессиональные сферы, где манипуляции считаются менее предосудительными, нежели чем в сфере межличностных отношений. Например, в педагогике без этого нельзя, так как дети являются стихийными манипуляторами, и, если педагог не применяет манипулятивные приемы, то управление детским коллективом является весьма проблематичным. Вопрос заключается лишь в том, чтобы подобное поведение не выходило за рамки соответствующих нравственных и моральных норм. Вся психотерапия (и наркология вместе с ней) немыслима без манипуляций. То же самое можно сказать об управленческой деятельности. Есть профессиональные сферы, где будущего специалиста намеренно обучают навыкам манипулятивного поведения. К таковым относятся тренинг продаж, сетевой маркетинг, продвижение услуг.

На наш взгляд, наиболее детальный психологический анализ является наиболее интересным в тех видах деятельности, которые возникли не так давно - а именно, В конце 80-х годов прошлого века. В нашей статье речь идет об области управления наёмным трудом. Именно в этой сфере манипуляции стали неотъемлемым атрибутом профессиональной деятельности.

Известно, что в процессе управления часто возникают задачи, которые необходимо решать ускоренно, в условиях дефицита времени, информации и ресурсов. Промедление влечет за собой тяжелые последствия не только для управляющего субъекта, но и для организационной структуры в целом. Соответственно, при этом возникает такая ситуация, где сама ситуация провоцирует менеджера прибегать к манипуляциям. Исследователь данной проблемы Е.Л. Доценко подчёркивает, что манипулятивные технологии не являются тотальным принуждением, так как всегда оставляют возможность для манёвра подчинёного [2]. Таким образом менеджерманипулятор предоставляет возможность подчинённому-манипулируемому реализовать себя в нужном для руководства направлении, но подчиненный в идеале должен сам выбрать для себя стратегию выполнения задачи. Таким образом, манипулятивные технологии со стороны менеджера могут быть более эффективными, чем открытое правление.

И вообще, офисная среда и работа менеджера, в частности, представляет собой «механообразную» среду, провоцирующую возникновение, увеличение и закрепление манипулятивных паттернов поведения.

Итак, нами была поставлена задача выяснить влияние профессионального опыта управленческой деятельности на сформированность манипулятивных способностей. Объем выборки составил 30 человек, менеджеры среднего звена в торгово-закупочной фирме, представляющей собой предприятие среднего бизнеса.

Для диагностики уровня манипулятивности мы использовали тест «Шкала манипулятивного отношения» Т. Банта. Данный тест выявляет склонность к манипулятивным паттернам поведения и отношение к партнеру по взаимодействию не как к личности, а как к инструменту достижения цели.

Также мы рассматривали сопутствующие манипулятивному поведению черты личности. Для этого нами были использованы еще два теста:

1. Опросник MACH-IV в адаптации В.В. Знакова. Его предназначение - измерение уровня макиавеллизма. Под макиавеллизмом здесь понимается готовность отступления от общепринятых социальных норм ради достижения каких-либо своих целей.

2. Шкала враждебности Кука-Медлей. Указанный опросник является трехфакторным, он оценивает уровень цинизма, агрессивности и враждебности при осуществлении социальных контактов.

- Для того, чтобы определить имеется ли какаято взаимосвязь между показателями макиавеллизма, агрессивности, враждебности, склонности к манипуляциям и стажем менеджеров в данной выборке, нами был применён корреляционный анализ. По показателям стажа выборка была разбита на 2 группы (группа № 1 - до 5 лет стажа, и группа № 2 - 5 и более лет стажа).

Для каждой из этих групп был проведен корреляционный анализ с построением корреляционных плеяд. Результаты представлены ниже.

Ядрами корреляционной плеяды в обоих случаях выступают показатели стажа и цинизма. Они имеют больше всего корреляционных связей. Из анализа представленных корреляционных плеяд мы можем сделать вывод, что на первом этапе профессиональной деятельности (при стаже менее 5 лет) имеет место отрицательная корреляция между показателями стажа и враждебности, а на втором этапе какая-либо достоверная взаимосвязь между показателями стажа и враждебности пропадает. То есть, мы предлагаем указанную закономерность проинтерпретировать следующим тезисом: по мере увели- 


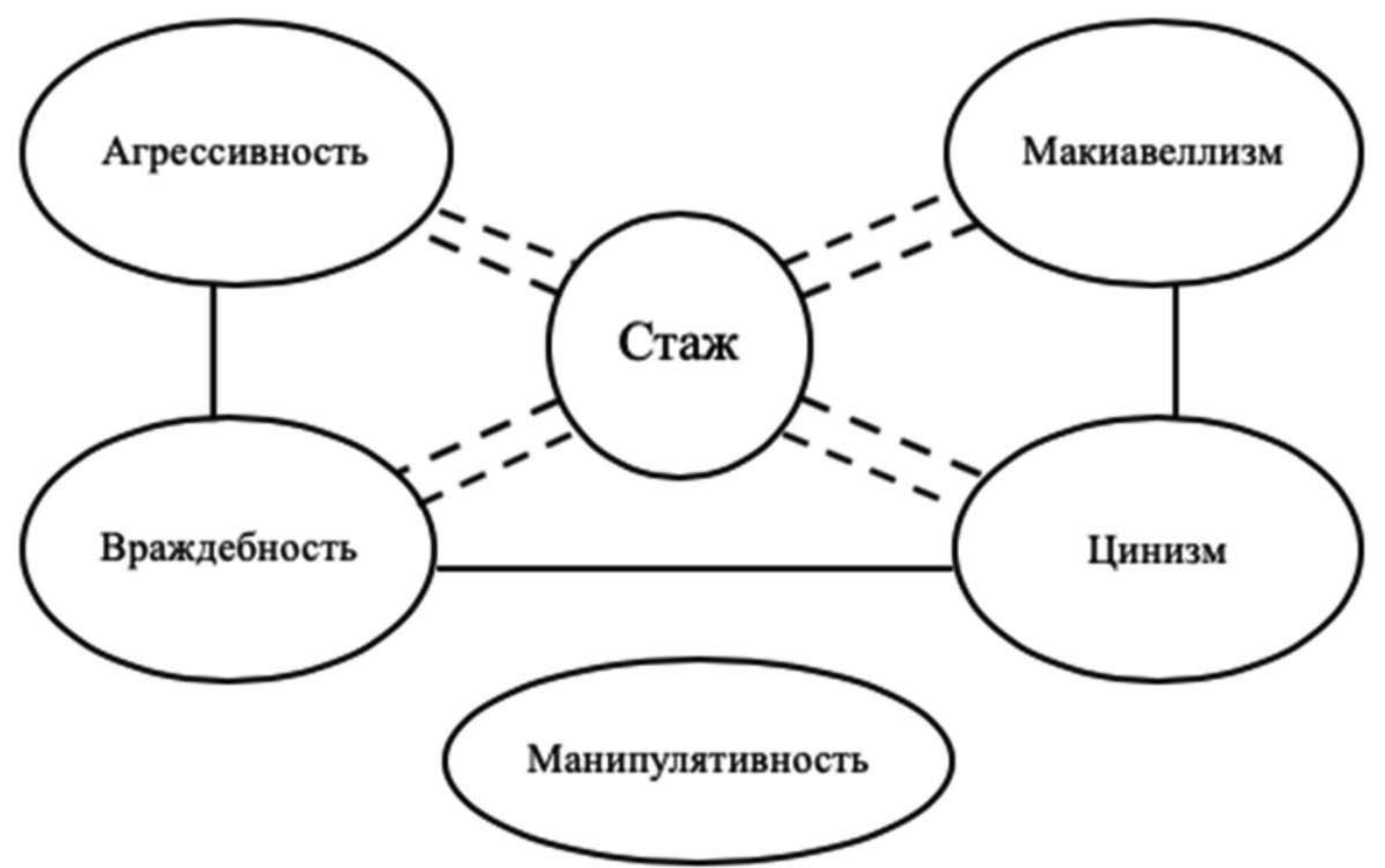

Диаграмма № 1. Плеяды для представителей проф. стажа до 5 лет

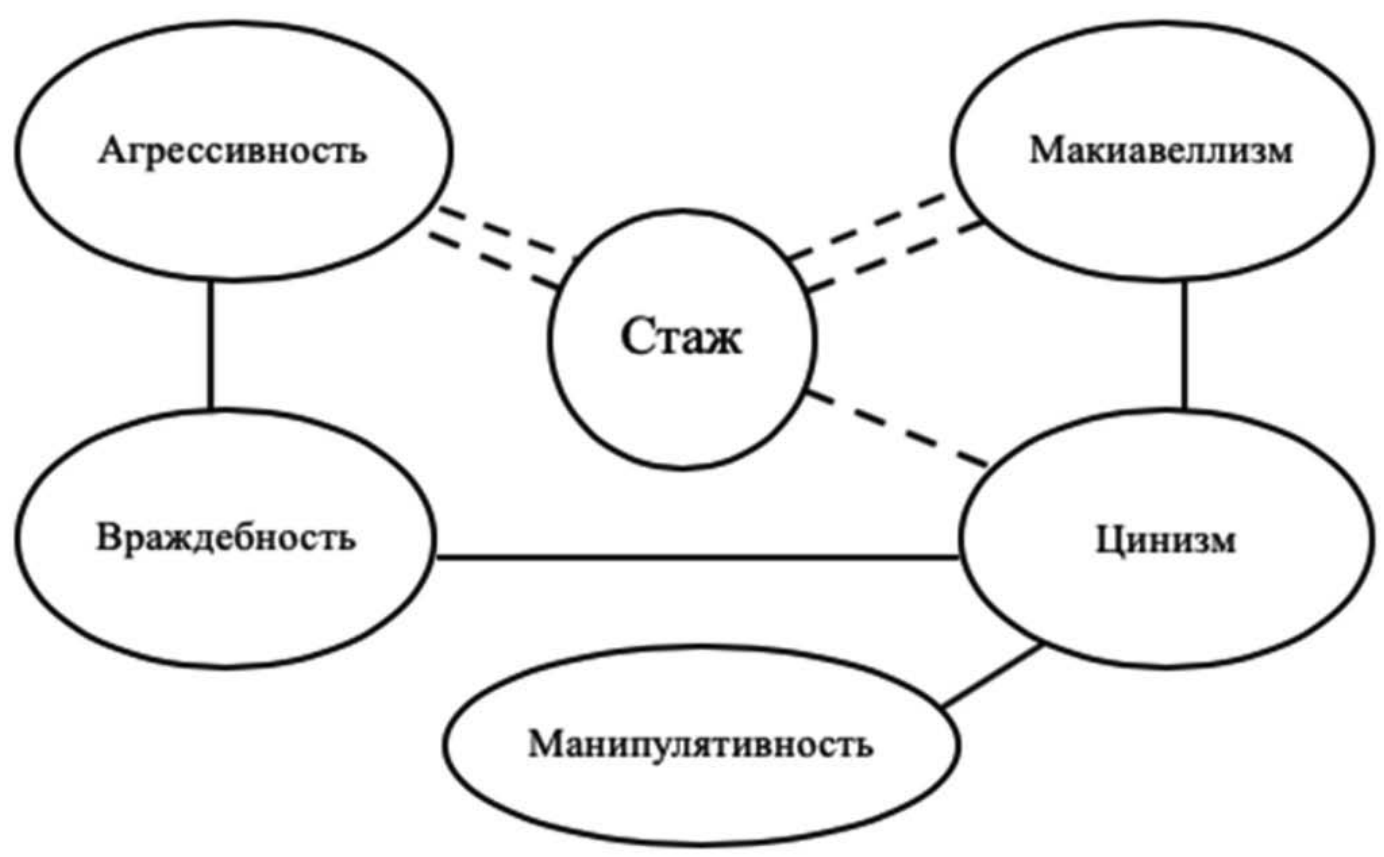

Диаграмма № 2. Плеяды для представителей проф. стажа от 5 и более лет

чения стажа, доминирование враждебных паттернов в общении уменьшается.

Также мы можем видеть, что по мере возрастания стажа падает достоверность взаимосвязи показателей стажа и проявлений цинизма, а манипулятивность как личностное качество начинает демонстрировать корреляционную зависимость с показателями цинизма. Таким образом, по мере увеличения стажа падает его взаимосвязь с уровнем цинизма, но возникает корреляционная связь показателей цинизма и склонности к манипулятивным паттернам в общении.

Для выявления зависимости уровня манипулятивности и стажа работы нами был выполнен анализ линейной регрессии с построением диаграммы рассеяния и вычислением регрессионного уравнения (был применен метод наименьших квадратов). Результаты приведены ниже. 


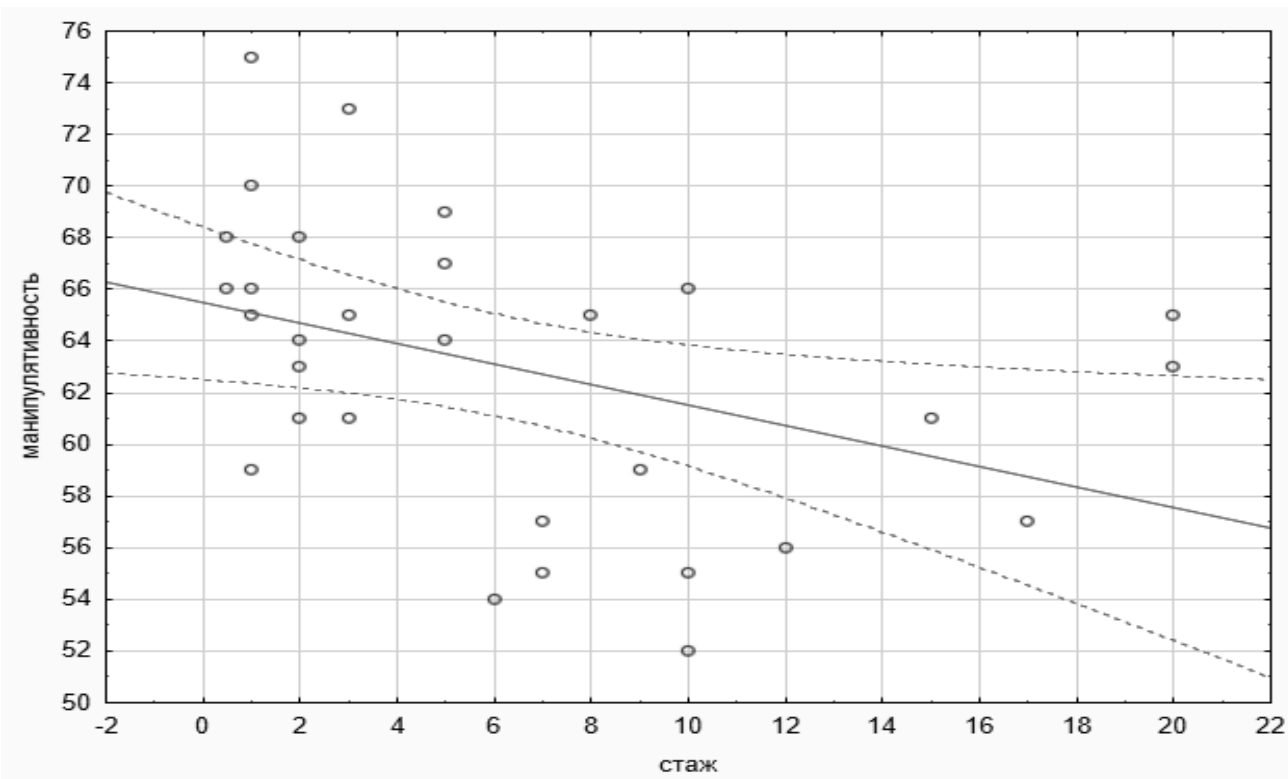

Диаграмма № 3. Диаграмма рассеяния показателей манипулятивности и стажа менеджера

На основании визуального анализа данного поля корреляции можно сделать вывод, что по мере увеличения стажа реализация манипулятивных способностей в общении падает.

На первый взгляд, этот вывод кажется неожиданным. Но, тем не менее, этому можно найти вполне разумное объяснение. Данная закономерность может быть связана с тем, что манипулирование является хорошей тактикой на непродолжительное время. Однако как полноценная долгосрочная стратегия поведения и управления людьми, она показывает неутешительные результаты. Мы можем предположить, что менеджерманипулятор создаёт в коллективе такую обстановку, где он ставит себя выше других и провоцирует этим напряжённость. Но чем дольше продолжаются манипуляции, чем дольше растёт напряжённость, тем меньше вероятность того, что сотрудника, порождающего подобную напряжённость, оставят на управленческой должности. Одновременно с тем, менеджеры на протяжении многих лет работы в достаточной степени повышают свою коммуникативную компетентность, и наличие манипулятивных паттернов поведения становится им нужным в значительно меньшей степени. То есть, менеджеры справляются с возникающими перед ними задачами и без применения манипуляций.

Также визуальный анализ корреляционного поля позволяет сделать вывод, что связь между всеми возможными значениями стажа менеджера (факторного признака) и показателями манипулятивности (результативного признака) носит линейный характер. Выведенное нами уравнение линейной регрессии имеет следу- ющую формулу:

\section{Уровень манипулятивности $=65,4657-0,3967 *$ показатель стажа}

Таким образом, зная показатель стажа менеджера, мы можем подставить его в приведенную выше формулу и с определенной долей вероятности предсказать его уровень манипулятивности.

Можно ли из этого сделать однозначный вывод, что у оптанта всегда по мере работы на должности менеджера падает потребность реализовывать манипулятивные паттерны поведения? Очень хотелось бы сделать именно такой вывод, но мы так однозначно заявлять не можем. Все дело в том, что мы тестировали только тех, кто являлся успешным менеджером. И за пределами диагностической процедуры оказались те оптанты, кто не проявил должного профессионализма и вынужден был уйти из профессии. То есть, мы предполагаем, что как раз лица с манипулятивными склонностями не задерживаются в профессии, а остаются в ней как раз те, кто стремится отказаться от манипулятивных шаблонов. Косвенным подтверждением этого утверждения является тот факт, что группы № 1 (до 5 лет стажа) и № 2 (5-20 лет) не смотря на разницу во временных отрезках являются равновесными: 14 и 16 человек, соответственно.

Однако, тем не менее, результаты проведенного нами исследования позволяют подтвердить выдвинутое нами предположение относительно того, что степень выраженности манипулятивных установок у менеджеров, отличающихся друг от друга показателями своего стажа, различна. 


\section{ЛИТЕРАТУРА}

1. Берн Э. Игры, в которые играют люди: Психология человеческих отношений. М, Эксмо, 2015.

2. Доценко Е.Л. Психология манипуляции: феномены, механизмы и защита.- М.: ЧеРо, 1997.

3. Литвак М.Е. Психологический вампиризм. Р/Д, Феникс, 2020.

4. Шостром Э. Анти-Карнеги. М, Попурри. 2004

○ Кутейников Алексей Николаевич (alex_kutejnikov@mail.ru).

Журнал «Современная наука: актуальные проблемы теории и практики»

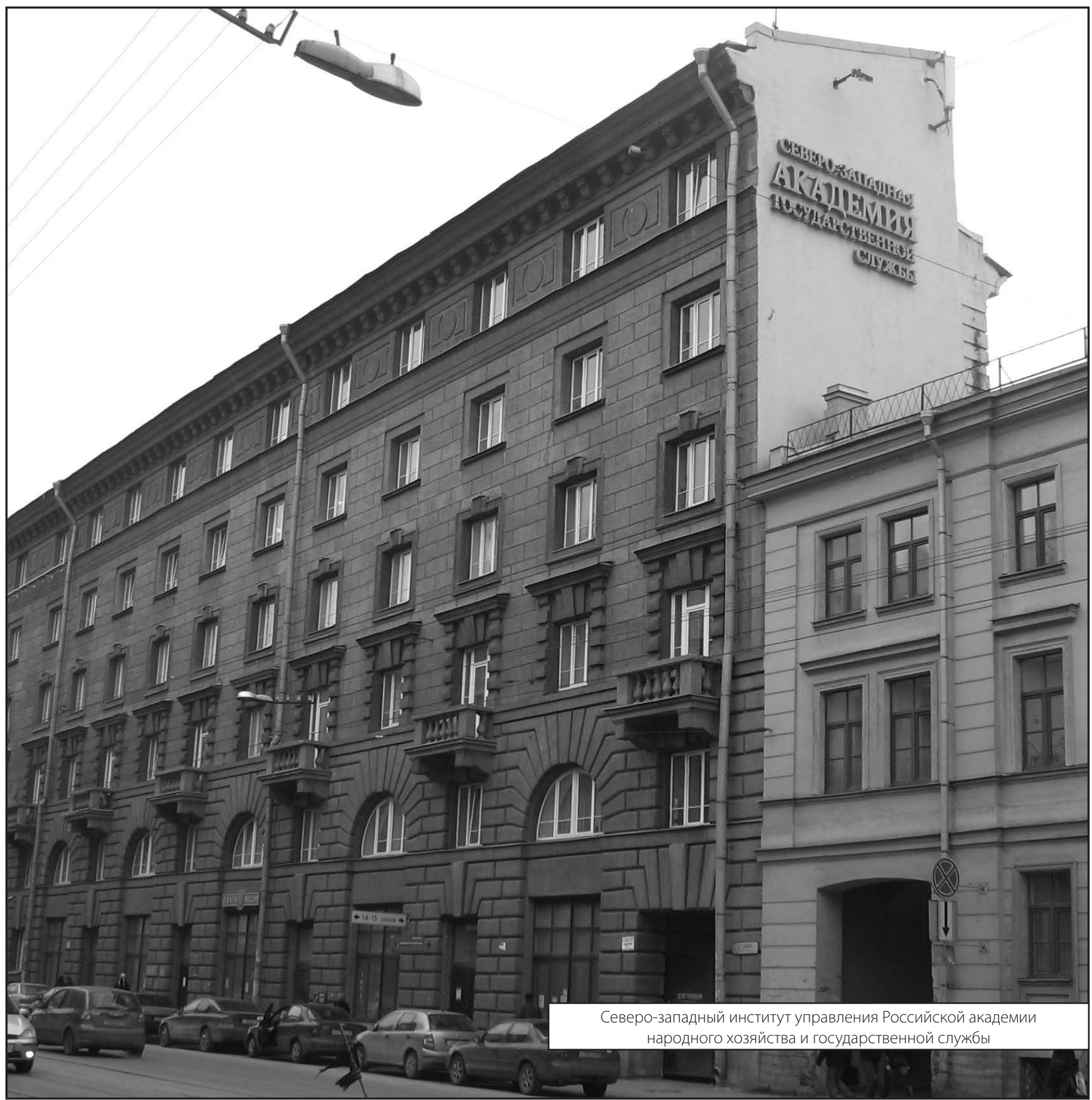

